\title{
One Way to Determine the Intervals in Hybrid Temporal Logic
}

\author{
Karavaev Eduard Fedorovich \\ Department of Logic, Institute of Philosophy, Saint Petersburg State University \\ 5 Mendeleevskaya Liniya, St. Petersburg, 199034, Russian Federation \\ E-mail: EK1549@ek1549.spb.edu
}

This presentation discusses the opportunity of improvement of technical means of hybrid temporal logic through the introduction of time intervals. In the procedure of constructing intervals the author of the presentation follows ideas and development expressed and carried out by A.A. Markov in his article published in 1932. So the 'Priorean paradigm' of understanding of the logic (temporal qualification of judgments and the idea of hybrid logic) is complemented by a building of time metric based on the relation 'earlier than'. It seems that the described improvement of the machinery of temporal logic allows, in particular, to perfect the approaches to the modelling of planning and strategic management.

Keywords: temporal logic, hybrid logic, satisfaction judgment, nominal-interval, discreteness of time, tree temporal structure, strategy, planning, management

\section{Introduction}

In standard ('Kripkean') semantics for temporal logic the truth-values of statements are correlated with some points in time. So we can translate from natural language to the formalized one, for example, the proposition "it's snowing" as $\boldsymbol{p}$, having in mind that it at different times has got different truth-values. Now, pay attention to the fact that there are judgments expressed in natural language which are true only in one particular time. For example, the judgment "it is five o'clock 4 December 1914 "1 is true (i.e., now "was true") at five o'clock 4 December 1914

\footnotetext{
${ }^{1}$ Recall that this is the date of birth of the founder of temporal logic Arthur Norman Prior, who has made also a substantial contribution to establishment of hybrid logic.
}

(c) Karavaev E.F. 
and is false during all other times (before and after the specified time). For a possibility of conversion from natural language to the formal language namely of such statements, i.e. the accounting of a highly specific characteristics of the logical form of thought is designed hybrid temporal logic.

In the hybrid logic a special kind of propositional letters is introduced. These letters are called nominals. The proposition designated by a given nominal expresses the judgment which is true only in one particular time. Thus the nominal designates some term which is correlated with a certain time. Another technical detail is the so-called satisfaction operators. Now the thought that the judgment "it's snowing" is true at five o'clock, 4 December 1914, or, closer to the natural way of speaking, "at five o'clock, 4 December 1914 it's snowing", can be presented on a formalized language of logical analysis well in a certain way; for example: @ ${ }_{\boldsymbol{a}} \boldsymbol{p}$. Here the nominal $\boldsymbol{a}$ stands for "it's five o'clock, 4 December 1914", and the 'ordinary' propositional $\boldsymbol{p}$ stands for "it's snowing"; the ingredient @ $\boldsymbol{a}_{\boldsymbol{a}}$ is the satisfaction operator. (Of course, in full the description of the design world point you need to specify the spatial coordinates; for example, for the new Zealand city Masterton the latitude and the longitude, respectively, are: $41^{\circ} 17^{\prime} 20^{\prime \prime} \mathrm{S}, 174^{\circ} 46^{\prime} 38^{\prime \prime} \mathrm{E}$; as for the third coordinates, that is, when choosing the centre of the Earth as a starting point, it is approximately equal to the value of the radius of Earth, $6371 \mathrm{~km}$.)

In general, if a is $\boldsymbol{a}$ nominal, and $\boldsymbol{\varphi}$ is any (well-formed) formula, then we will call the formula $@_{a} \varphi$ a satisfaction judgment. In addition to nominals and satisfaction operators, in hybrid logic we use the socalled delimiters $\square$ and $\downarrow$ which enable us to construct formulas of form $\square_{w} @_{a} \varphi$ and $\downarrow_{w} @_{a} \varphi$. Delimiters bound an occurrence of nominals: a delimiter of the type $\square$ carries out quantification of time moments like a universal quantifier and the delimiter of the type $\downarrow$ acts like an existential quantifier. More precisely: $\square_{\boldsymbol{w}} @_{\boldsymbol{a}} \boldsymbol{\varphi}$ is true in some possible world $\boldsymbol{w}$ if and only if whenever a nominal $\boldsymbol{a}$ applies to it the formula $\boldsymbol{\varphi}$ the formula is true in relation to this world $w ; \downarrow_{w} @_{a} \varphi$ is true in some possible world $\boldsymbol{w}$ if and only if $\boldsymbol{\varphi}$ is true in relation to this world $\boldsymbol{w}$ and the nominal $\boldsymbol{a}$ is applies to the world $\boldsymbol{w}$. 


\section{An improvement of technical means of hybrid temporal logic}

It is possible, on the basis of the A.A. Markov's work (1932) [13] $)^{2}$, to offer a way of definition for a nominal interval. Let $\boldsymbol{x}$ and $\boldsymbol{y}$ be two world (space-time) points, and $\boldsymbol{x}$ is earlier than $\boldsymbol{y}$; we denote this asymmetrical and transitive relation by $\boldsymbol{x} \prec \boldsymbol{y}$. We introduce the notion of chain: if $\boldsymbol{x}$ and $y$ are the world points and (1) $z_{0}, z_{1}, z_{2}, z_{3}, \ldots, z_{\mathrm{n}}$ is such a finite sequence that (2) $x=z_{0} \prec z_{1} \prec z_{2} \prec z_{3} \prec \ldots \prec z_{\mathrm{n}}=y$, then the sequence (1) is the chain between $\boldsymbol{x}$ and $\boldsymbol{y}$.

Each of oriented pairs $\left(z_{\mathrm{i}-1}, z_{\mathrm{i}}\right), \mathrm{i}=1,2,3, \ldots, \mathrm{n}$ which satisfies the condition $z_{\mathbf{i}-\mathbf{1}} \prec z_{\mathbf{i}}$ is called a link of the chain. Further, introduce the postulate of finiteness: the chain between any two points may not contain arbitrarily large number of links. Note that the introduction of such the postulate of finiteness is, of course, the recognition of the discreteness of time. Recall, however, that according to the V.A. Kotelnikov's theorem (1933) [12], a function, the range of changes which is limited to a certain frequency $\boldsymbol{F}_{e}$, can be fully represented by the sequence of its readout values that follow each other with the following time interval: $1 / 2 \boldsymbol{F}_{e}$.

Next, introduce an atomic relation. Let (1) $z_{\mathrm{i}-1}=z_{\mathrm{i}, 0} \prec z_{\mathbf{i}, 1} \prec$ $z_{\mathrm{i}, 2} \prec z_{\mathrm{i}, 3} \prec \ldots \prec z_{\mathrm{i}, \mathrm{m}(\mathrm{i})}=z_{\mathrm{i}}$ where $\mathbf{i}=1,2,3, \ldots, \mathbf{n}$ are $\mathbf{n}$ chains between all successive (1). If in doing so there is at least one element $\mathbf{m}(\mathbf{i})$ which different from 1 among $\mathbf{n}$ integers we say that the chain (4) $x=z_{0,0} \prec z_{0,1} \prec z_{0,2} \prec z_{0,3} \prec \ldots \prec z_{0, \mathrm{~m}(0)} \prec z_{1,0} \prec z_{1,1} \prec$ $z_{1,2} \prec z_{1,3} \prec \ldots \prec z_{1, \mathrm{~m}(1)} \prec z_{2,0} \prec z_{2,1} \prec z_{2,2} \prec z_{2,3} \prec \ldots \prec$ $z_{2, \mathrm{~m}(2)} \prec z_{\mathrm{i}, 0} \prec z_{\mathrm{i}, 1} \prec z_{\mathrm{i}, 2} \prec z_{\mathrm{i}, 3} \prec \ldots \prec z_{\mathrm{i}, \mathrm{m}(\mathrm{i})} \prec \ldots \prec z_{\mathrm{n}, 0} \prec$ $\mathbf{z}_{\mathbf{n}, \mathbf{1}} \prec z_{\mathbf{n}, \mathbf{2}} \prec \mathbf{z}_{\mathbf{n}, \mathbf{3}} \prec \ldots \prec z_{\mathbf{n}, \mathbf{m}(\mathbf{n})}=\boldsymbol{y}$ is obtained from the chain (1) by means of its refinement. Obviously, if the postulate of finiteness has been introduced, the procedure of refinement cannot last forever. So we come to the concept of a saturated chain. A single-link saturated chain is a chronus and an arbitrary saturated chain is a chronusean chain.

Let $\boldsymbol{x} \prec \boldsymbol{y}$. With the postulate of finiteness, natural numbers, representing the number of chain links between $\boldsymbol{x}$ and $\boldsymbol{y}$ form a limited

\footnotetext{
${ }^{2}$ The author of this article was acquainted with the translation of the Markov's work thanks to his teacher and Markov's pupil, N.A. Shanin (in the late 1980s); the translation was made by R.I. Pimenov.
} 
set. And so among them there is the largest number that represents the maximum number of links in the chains between $\boldsymbol{x}$ and $\boldsymbol{y}$. And you can define a positive integer function: $\sigma(\boldsymbol{x}, \boldsymbol{y})$ is defined if and only if $\boldsymbol{x} \prec \boldsymbol{y}$; $\sigma(\boldsymbol{x}, \boldsymbol{y})=\mathbf{1}$ if and only if the pair $(\boldsymbol{x}, \boldsymbol{y})$ forms the chronus.

Thus, the relation 'earlier than', satisfying the postulate of finiteness, induces a metrics of time intervals. We got a natural measure for time intervals: number $\sigma(\boldsymbol{x}, \boldsymbol{y})$ is a measure of the interval $(\boldsymbol{x}, \boldsymbol{y})$. And if the world points $\boldsymbol{a}$ and $\boldsymbol{b}$ are nominals and, together with it, are the end points of the line formed by the other world points, which are also the nominals we obviously get an interval-nominal or a nominal interval. (Note that the delimiter of the type $\square$ is not a thing like that: it's not bringing us to the metrics of time.)

Note that to use the discrete time structure is quite realistic, in terms of cognitive processes. For example, research performed by J.M. Stroud [18], and research performed by R. Efron [2] have shown that the minimum perceived quantum of simultaneity of two events is $60-100 \mathrm{msec}$. Currently the opinion that the perception of time is discrete, reinforced by numerous experienced data, is widespread ([19]). It seems that the mechanism that causes the discreteness of the perception of time can be explained by the "theory of the scanning alpha rhythms', which was proposed by the outstanding American-born British neurophysiologist and robotician W. Grey Walter [3]. Alpha-rhythm is a scanning mechanism of the brain and due to the dissemination of wave excitation on the bark of the big hemispheres. Such a 'scanning' is carried out in the rhythm of 80-120 ms. In between waves of the excitation brain cells are not active. So between the two outbreaks of alpha-activity the temporal order does not matter.

\section{An improvement of approaches to the modeling of planning and strategy management}

Following the 'Priorean paradigm' of understanding of logic (see her detailed presentation in: [14], I first tried to combine various qualifications logical form of thoughts, especially emphasizing the importance of the temporal qualifications, and, secondly, relied on the model of the discrete time (see [5-8]). 
It is possible to show how in the framework of the Priorean paradigm we can improve approaches to the modelling of planning and strategic management. We have done it in some articles (see [9-11]). The articles deal with an analytical account of the H. Simon's conception of 'bounded rationality' (see [16-17]) and make a substantial addendum to it. It concerns the famous 'Condorcet's paradox' and the impossibility of building a 'flawless' regulatory code. Further, these deal with some considerations of possibilities to apply the means of nonclassic logic (temporal, deontic, alethic modal, epistemic, hybrid logic and logic of agency) for improvement of formalized representation of planning procedures. Ways of improvement of afore-mentioned model are employing M. Raynor's experimental data (and theoretical ideas) connected with the 'strategy paradox' are suggested (see [15]).

The structure of plan of our actions related to the achievement of some objective may be presented by means of a tree temporal structure (or 'branching time') that is used in the semantic development of temporal logic. A constructed tree structure, of course, will not be 'perfect'. Every branching and total number of them it is possible to determine only approximately. Limitations of our rationality are conditioned by many factors: (1) the lack of complete information about a set of alternatives; (2) the complexity of the calculation of alternatives and, as a result, the inability to them all; (3) the uncertainty of the effects to be expected from each alternative. We will also always remember the time factor and the principle ceteris paribus, i.e. positing that the factors which, as we suppose, do not change during the time when interesting for us situation takes place may be ignored. In psychology, the provisions of this kind are described with using the concept of 'the level of claims'. Psychological and epistemological aspects of the named principle successfully set out by D. Kahneman: WYSIATI, i.e. "What you see is all there is" (see [4, pp. 85-88]).

So it is not possible to speak not only about creating optimum, i.e. generally the best strategy: we cannot ensure even satisfactory strategy, i.e., best of the many alternatives that we watch, and we can have only the strategy, which meets certain goals and criteria at a certain level. 
In the branching points of the structure, we meet with the 'Condorcet's paradox' (see [1]). It may happen, for example, that three alternative continuations of the plan ('the branches of the tree') $\boldsymbol{A}, \boldsymbol{B}$ and $C$ which are valued, for example, again, in respect of three parameters, are such ones that the first of them is better than the two others in respect of the first characteristics, the second - in respect of the second and the third - in respect of the third. The proportion of this kind of possible 'deadlocks' is quite considerable - about from 5.6\% to 8.8\%. This is the so-called 'Condorcet's effect'. Obviously, we have to use some additional considerations. For example, considering that since none of the alternatives is worse than the other, to select it. But, notice that we do not know what 'the road ahead'.

Raynor, with very representative data (obtained in his work in the consulting firm), noticed that the most successful companies often have more in common with companies that failed and no longer in business, than they do with companies that have managed merely to survive. The successful companies, as well as many of the failed ones, aimed to be leaders in their industries and market segments. The former made it. The latter did not. The 'strategic trees' of companies-losers are not worse than ones of successful companies; both those and others may be equally 'great'. Often, the only discernible difference between the two is the element of luck (or bad luck). In other words, it often happens so, that the strategy of the 'lucky' is much more similar to the real objective course of events than a strategy of 'loser'. You can even say so: it happens that the strategy most likely to have success also most likely to be a failure.

Importance of the hybrid logic for the analyzed here theme of formalization, i.e. of introducing clarity into descriptions of procedures of planning activities, is quite obvious. In fact, using these funds, we 'bind' our plan to the real calendar (and the real clocks). In addition, the use of intervals can overcome some technical difficulties relating to the construction of function of distribution of random variables related to the points of branching 'strategic tree'. This question requires special consideration and is linked with the fact that the probability of any particular value of a continuous random variable equal to zero. 
We don't want to end our consideration on the 'somber note'. Strategies must, by definition, be based on our best assumptions about the future, but that future will change in ways that we did not foresee. In real life events will happen that we never anticipated and to which we must react. For 'doing nothing' is also a strategy. Raynor reminds a thought of Louis Pasteur that in science luck favors the prepared mind, which is looking for her. Let us add this idea by the Russian saying: "Ah! Misfortune has no mater"3 . Or by English one: "Hope for the best and prepare for the worst".

\section{References}

[1] Arrow, K.J. Social Choice and Individual Values. New York; London; Sydney: John Wiley and Sons, Inc., 1964. 124 pp.

[2] Efron, R. "Conservation of temporal information by perceptual systems", Percept Psychophys, 1973, vol. 14, pp. 518-530.

[3] Grey Walter, W. The Living Brain. London: Pelican Books, 1963. 311 pp.

[4] Kahneman, D. Thinking, fast and slow. New York.: Farrar, Straus and Giroux, 2011. 499 pp.

[5] Karavaev, E.F. "On some logical principles in resolving of moral problems", in: Ethics in Sciences. Workshop, 14-16 July, 1997 at Tuebingen. Reader: Statements/ Lectures. Tuebingen: Internatoinales Zenttrum, 1997, pp. 41-53.

[6] Karavaev, E. F. "Logic and Moral Dilemmas", in: The Proceedings of the Twentieth World Congress of Philosophy (Boston, 10-16 August, 1998) [http://www.bu.edu/wcp, accessed on 01.06.2016].

[7] Karavaev, E.F. "On temporal qualification of normative propositions", in: Vos'mye Smirnovskie chteniya po logike [The 2th International Conference "Smirnov's Readings"] (Moscow, May 1999). Moscow: IF RAS, 1999, pp. 111-114. (In Russian)

[8] Karavaev, E.F. "A deontic logic with temporal qualification", in: Time and history. Proceedings of the 28 International Ludwig Wittgenstein Symposium, ed. by Fr. Stadler, M. Stö ltzner. Frankfurt et el.: Ontos Verlag, 2006, pp. 459-467.

\footnotetext{
${ }^{3}$ Perhaps, this is the best English translation of proverb, proposed by A.S. Pushkin in his 'Captain's daughter' at the beginning of the third chapter. It was made by M.H. de Zielinska. (Pushkin, A.S. A Story of Russian Love. Chicago, 1914, p. 53).
} 
[9] Karavaev, E.F. 'Dopolnenie contseptsii 'ogranichennoy ratsional'nosti' Saimona" [An addition of the Simon's concept of 'bounded rationality'], Vestnik Sankt-Petersburgskogo Gosudarstvennogo Universiteta [The Bulletin of the Saint-Petersburg State University], 2002, series 6, issue 3, pp. 33-37. (In Russian)

[10] Karavaev, E.F. "Sredstva neclassicheskoy logiki dlya formalizatsii protsedur planirovania" [The means of non-classical logic for formalization of planning procedures], Vestnik Sankt-Petersburgskogo Gosudarstvennogo Universiteta [The Bulletin of the Saint-Petersburg State University], 2008, series 6, issue 1, pp. 87-94. (In Russian)

[11] Karavaev, E.F. "Ob usovershenstvovannoy logicheskoy modeli planirovania na osnove eksperimental'nykh dannykh o «paradokse strategii»" [On improving logical model of planning on the basis of experimental data of a «paradox strategy»], Vestnik SanktPetersburgskogo Gosudarstvennogo Universiteta [The Bulletin of the Saint-Petersburg State University], 2009, series 6, issue 3, pp. 97-105. (In Russian)

[12] Kotelnikov, V.A. "On the transmission capacity of the 'ether' and of cables in electrical communication" $[\mathrm{O}$ propusknoy sposobnosti efira i provoloki v elektrosvyazi], in: Materialy $k I$ Vsesouznomu s'ezdu po voprosam tekhnicheskoy rekonstrukcii dela svyazi $i$ razvitiya slabotochnoy promyshlennosti [Proceedibgs of the 1st All-Union Conference on Technological Reconstruction of the Communication and Low-Current Engineering]. Translation by C.C. Bissell and V.E. Katsnelson, Moscow, 1933, pp. 1-19.

[13] Markoff A. "Uber die Ableitbarkeit der Weltmetrik aus der «Fruher Als»Beziehung", Physikalische Zeitschrift der Soviet Union. 1932, band 1, heft 3, ss. 387-406.

[14] Øhrstrøm, P., Hasle, Per F.V. Temporal Logic: from Ancient Ideas to Artificial Intelligence. Dordrecht, The Netherlands: Kluwer Academic Publ. Group, 1995. 414 pp.

[15] Raynor, M. E. The Strategy Paradox: Why Committing to Success Leads to Failure (and What to do about it). New York: Doubleday Books, 2007. $320 \mathrm{pp}$.

[16] Simon, H. The sciences of the artificial. Cambridge, Mass.: The MIT Press, 1969. 246 pp.

[17] Simon, H. "Rational decision making in business organizations", The American economic review. 1979, vol. 69, issue 4, pp. 493-513. 
[18] Stroud, J.M. "The fine structure of psychological time", in: Annals of the New York Academy of Sciences. 1967, vol. 138. (Interdisciplinary Perspectives of Time), pp. 623-631; originally published as: Stroud, J. M. "The fine structure of psychological time", Information theory in Psychology, ed. by H. Quastler. Chicago, Ill: Free Press. 1956, pp. 174-205.

[19] Van Rullen, R., Koch, C. "Is perception discrete or continuous?", Trends in Cognitive Sciences, 2003, Vol. 7, No. 5 (May), pp. 207-213. 